dependent on FXa-activated FV. Once generated, thrombin would counter this effect of TFPI $\alpha$ by producing forms of activated FV that have been cleaved at R1545 and lack the potential TFPI $\alpha$-binding site AR.

Is there a role for PS? PS is known to interact with FXa, FV(a), and TFPI $\alpha$ and is also released by stimulated platelets. Thus, its potential role in the reactions discussed above warrants investigation.

Most important to the affected members of the east Texas family, however, is that the elucidation of the underlying pathophysiology suggests that TFPI inhibitors currently in development may provide a means of treatment $(14,15)$.

\section{Acknowledgments}

George Broze is funded by NIH grant R37 077193.

Address correspondence to: George J. Broze Jr., Division of Hematology, Campus Box 8125, Washington University School of Medicine, 660 South Euclid Avenue, St. Louis, Missouri 63110, USA. Phone: 314.362.8811; Fax: 314.362.8813; E-mail: gbroze@dom.wustl.edu.

1. Broze GJ Jr, Warren LA, Novotny WF, Higuchi DA, Girard JJ, Miletich JP. The lipoprotein-associated coagulation inhibitor which inhibits the factor VII-tissue factor complex also inhibits factor Xa: Insight into its possible mechanism of action. Blood. 1988;71(2):335-343.

2. Hackeng TM, Sere KM, Tans G, Rosing J. Protein S stimulates inhibition of the tissue factor pathway by tissue factor pathway inhibitor. Proc Natl Acad Sci US A. 2006;103(9):3106-3111.

3. Ndonwi M, Tuley EA, Broze GJ Jr. The Kunitz-3 domain of TFPI-alpha is required for protein $\mathrm{S}$-dependent enhancement of factor Xa inhibition. Blood. 2010;116(8):1344-1351.

4. Duckers C, et al. Low plasma levels of tissue factor pathway inhibitor in patients with congenital factor V deficiency. Blood. 2008;112(9):3615-3623.

5. Castoldi E, Simioni P, Tormene D, Rosing J, Hackeng TM. Hereditary and acquired protein $\mathrm{S}$ deficiencies are associated with low TFPI levels in plasma. J Thromb Haemost. 2010; 8(2):294-300.

6. Ndonwi M, Girard TJ, Broze GJ Jr. The C-terminus of tissue factor pathway inhibitor $\alpha$ is required for its interaction with factors $\mathrm{V}$ and Va.J Thromb Hae- most. 2012;10(9):1944-1946

7. Monkovic DD, Tracy PB. Functional characterization of human platelet-released factor $\mathrm{V}$ and its activation by factor Xa and thrombin. J Biol Chem. 1990;265(28):17132-17140.

8. Bos MHA, Camire RM. A bipartite autoinhibitory region within the B-domain suppresses function in factor V. J Biol Chem. 2012;287(31):26342-26351.

9. Kuang SQ, et al. Characterization of a novel autosomal dominant bleeding disorder in a large kindred from east Texas. Blood. 2001;97(6):1549-1554.

10. Vincent LM, et al. Coagulation factor $V^{A 2440 G}$ causes east Texas bleeding disorder via TFPI $\alpha$. J Clin Invest. 2013;123(9):3777-3787.

11. Huang Z-F, Wun T-C, Broze GJ Jr. Kinetics of factor $\mathrm{Xa}$ inhibition by tissue factor pathway inhibitor. J Biol Chem. 1993;268(36):26950-26955.

12. Mast AE, Broze GJ Jr. Physiological concentrations of tissue factor pathway inhibitor do not inhibit prothrombinase. Blood. 1996;87(5):1845-1850.

13. Monkovic DD, Tracy PB. Activation of human factor $\mathrm{V}$ by factor $\mathrm{Xa}$ and thrombin. Biochemistry. 1990;29:1118-1128.

14. Hilden I, et al. Hemostatic effect of a monoclonal antibody mAb 2021 blocking the interaction between FXa and TFPI in a rabbit hemophilia model. Blood. 2012;119(24):5871-5878.

15. Gorczyca ME, et al. Inhibition of tissue factor pathway inhibitor by the aptamer BAX499 improves clotting of hemophilic blood and plasma. JThromb Haemost. 2012;10(8):1581-1590.

\title{
A "Tric" to tighten cell-cell junctions in the cochlea for hearing
}

\author{
Tomohito Higashi, ${ }^{1}$ Danielle R. Lenz, ${ }^{2}$ Mikio Furuse, ${ }^{1}$ and Karen B. Avraham ${ }^{2}$
}

\begin{abstract}
1Division of Cell Biology, Department of Physiology and Cell Biology, Kobe University Graduate School of Medicine, Kobe, Japan. 2Department of Human Molecular Genetics and Biochemistry, Sackler Faculty of Medicine, and Sagol School of Neuroscience,
\end{abstract} Tel Aviv University, Tel Aviv, Israel.

\begin{abstract}
Tricellulin is a tricellular tight junction-associated membrane protein that controls movement of solutes at these specialized cell intersections. Mutations in the gene encoding tricellulin, TRIC, lead to nonsyndromic deafness. In this issue of the JCI, Nayak et al. created a gene-targeted knockin mouse in order to mimic the pathology of a human TRIC mutation. Deafness appears to be caused either by an increase in the $\mathrm{K}^{+}$ion concentration around the basolateral surfaces of the outer hair cells or, alternatively, by an increase in small molecules such as ATP around the hair bundle, leading to cellular dysfunction and degeneration. Furthermore, the mice have features suggestive of syndromic hearing loss, which may have implications for care and treatment of patients harboring TRIC mutations.
\end{abstract}

Millions worldwide suffer from a debilitating hearing loss (1). In many regions of the world in which health care conditions and public health are less developed or in populations with high rates of consanguinity, the number of people affected is extremely

Conflict of interest: The authors have declared that no conflict of interest exists.

Citation for this article: J Clin Invest. 2013; 123(9):3712-3715. doi:10.1172/JCI69651. high. Understanding the mechanisms leading to hearing loss may help widen the current scope of therapeutic options, which are currently restricted to hearing aids and cochlear implants. The causes of hearing loss are manifold, including both genetic and environmental factors. Hereditary hearing loss is caused by mutations in a wide variety of genes that encode the proteins associated with the transduction of sound waves from the external ear to the middle and inner ear and finally to the brain. To date, hereditary hearing loss has been linked to over 60 genes (2).

The cochlea, located in the inner ear, is responsible for the conversion of sound to a neural electric excitatory signal (3). Two distinct fluids, the endolymph and perilymph, are contained within the cochlea. While the perilymph has an ionic composition similar to that of the general extracellular fluid, the endolymph is characterized by a high $\mathrm{K}^{+}$concentration and endocochlear potential (EP), which are essential for hearing (4). An epithelial cellular sheet covering the cochlea creates a barrier that allows these fluids to maintain their composition.

\section{Tight junctions are essential for sound conduction}

Tight junctions (TJs) provide a strong epithelial barrier function within the cochlea, preventing the leakage of solutes through 


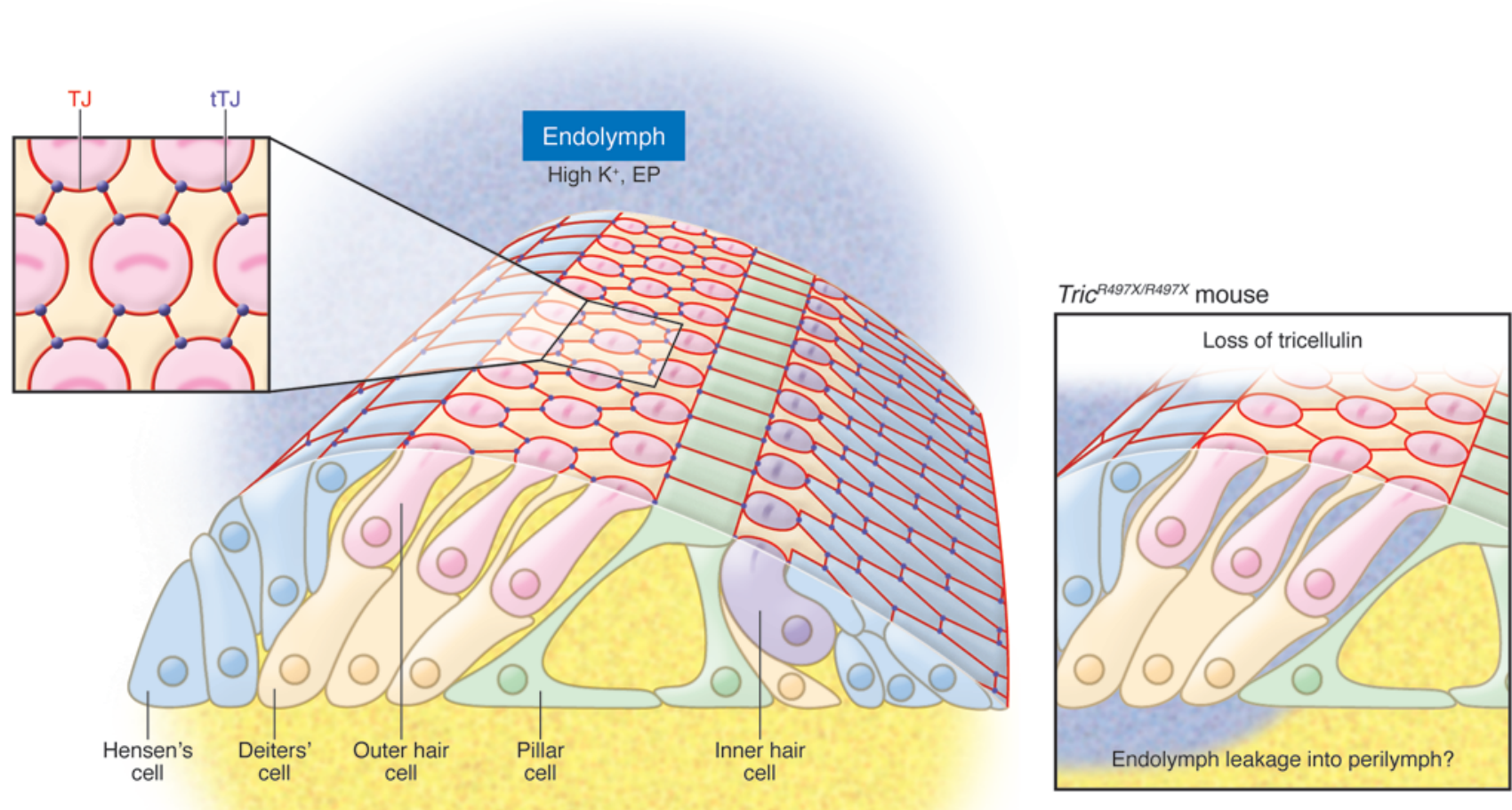

Perilymph

\section{Figure 1}

The mammalian organ of Corti contains the sensory epithelium essential for hearing, including hair and supporting cells. The hair cells include both inner and outer hair cells, and the supporting cells include Hensen's cells, Deiters' cells, and pillar cells. A crucial parameter of the organ of Corti is the ionic composition of the perilymph and endolymph, held in balance by the epithelial sheet that contains TJs. A further demarcation of the TJs are the tTJs, which when impaired in Tric mutant mice are postulated to lead to endolymph leakage into the perilymph. This aberration would have dire consequences for hearing.

the intercellular space (5). TJs surround each epithelial cell at the boundary of the apical and basolateral membrane domains, sealing the intercellular space like a zipper (6). Consequently, the apical side of the cells faces a high potassium solution, the endolymphatic fluid, while the basolateral side contacts the perilymphatic fluid (ref. 7 and Figure 1).

$\mathrm{TJ}$ proteins have been localized to the inner ear, and a number of them have been implicated in hearing. These include the claudin family of membrane proteins, which are essential components of TJs. CLDN14 was identified as the causal gene in human hereditary deafness at the DFNB29 locus (8), and Cldn14 knockout mice exhibit hearing loss with degeneration of hair cells (9). Cldn9 mutant mice also exhibit deafness with hair cell degeneration (10). Mice lacking the Cldn11 gene, which is expressed in the stria vascularis, suffer from deafness and a loss of the EP $(11,12)$. In addition, overexpression of ZO-2 (also known as TJ protein 2 [TJP2]), a TJ-associated scaffold protein that binds to claudins, leads to nonsyndromic hearing loss DFNA51, mediated by the GSK-3 $\beta$ pathway (13). These observations indicate that the TJ-mediated permeability barrier in the cochlea is essential for hearing.

\section{The TRIC to listening}

Although it is not well recognized, the paracellular pathway within the cellular sheet can be spatially divided into two parts: one between two adjacent cells and the other at tricellular contacts (TCs) where the vertices of three cells meet. It is not easy to grasp how the "TJ zipper" seals the intercellular space at the TCs, because there are three plasma mem- branes. Electron microscopic studies have revealed that there are specialized structures of TJs at the TCs, named tricellular TJs (tTJs), which make the extracellular space at TCs reach their limit of narrowness (14). Previously, Saima Riazuddin and colleagues had reported that TRIC, which encodes a tTJ-associated membrane protein, tricellulin (15), is causally linked to nonsyndromic hereditary hearing loss, DFNB49 (16). In this issue of the JCI, in an elegant follow-up study to determine the mechanism of TRIC-associated deafness, Nayak et al. generated Tric R497X/R497X knockin mice, which mimic a human DFNB49 mutation (17). Following the observation of a phenotype consistent with profound deafness by auditory brainstem response, Nayak et al. examined the morphology of the cells of the inner ear and noted hair cell degeneration, followed 
by the demise of spiral ganglion cells by postnatal day 30. Freeze-fracture replica electron microscopy revealed that the $\mathrm{tTJ}$ were not normally formed among hair and supporting cells in the organ of Corti in $\operatorname{Tric}^{R 497 X / R 497 X}$ mice; the sealing elements of $\mathrm{TJ}$ s were not integrated into typical $\mathrm{tTJ}$ s at the center of TC regions. A similar phenotype was seen at the TCs in the utricular macula (vestibular organ). These observations clearly demonstrate that tricellulin is essential for $\mathrm{tT}$ formation in the cochlea at the ultrastructural level, leading to impairment of epithelial barrier function at the TCs. Impairment of tTJ formation may thus lead to the leakage of small molecules through the TCs. Indeed, tricellulin knockdown in cultured epithelial cells results in a reduction of epithelial barrier function, as evaluated by the measurements of transepithelial electrical resistance as well as paracellular flux (15).

\section{Cochlear hair cell degeneration}

Perhaps the most compelling experiment performed by Nayak et al. was the attempt to discern why the hair cells of the Tric ${ }^{R 497 X / R 497 X}$ mice die. Was hair cell death due to disrupted hair cell function or to an altered microenvironment around these cells? To address this question, they used a mouse model for the human form of

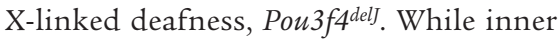
ear endolymph in this model has a reduced EP, mice harboring this allele have no organ of Corti defects. The authors asked whether changes induced in the Tric R497X/R497X mouse endolymph were able to rescue the hair cell degeneration in Pou $3 f 4^{d e l J}$ mice. Remarkably, the double mutants had no hair cell degeneration, suggesting that eliminating the extracellular factors from the stria vascularis and endolymph, not intracellular signaling between the hair cells, led to rescue of the phenotype (17). A most likely candidate for being this extracellular factor is the elevated $\mathrm{K}^{+}$ion concentration at the basolateral compartment of hair cells (Nuel's space). The high concentration of $\mathrm{K}^{+}$has been reported to cause degeneration of hair cells in mice deficient in $\mathrm{KCC} 3$ or $\mathrm{KCC} 4$, which are responsible for the retrieval of $\mathrm{K}^{+}$ions from Nuel's space $(18,19)$. On the other hand, the authors speculated that there may be minimal leakage of $\mathrm{K}^{+}$ion, based on the normal EP of the knockin mice, and proposed the possibility of leakage of other molecules, such as $\mathrm{Na}^{+}$and ATP. However, in Cldn9 mutant mice, which also exhibit an unaltered $\mathrm{EP}$, the $\mathrm{K}^{+}$concentration in the perilymph increased significantly (10). Hence, the possibility of $\mathrm{K}^{+}$leakage from the Tric ${ }^{R 497 X / R 497 X}$ mouse endolymph cannot be excluded. Judging from the fact that Cldn14-deficient mice, Cldn9 mutant mice, and Tric ${ }^{R 497 X / R 497 X}$ mice share the deafness phenotypes with unchanged EP and hair cell degeneration all within the same time frame, a common mechanism may underlie deafness in these models. Future studies may be able to clarify whether only subtle $\mathrm{K}^{+}$leakage, which does not affect the EP or endolymphatic ion compositions, can induce hair cell degeneration and whether the leakage of other molecules, such as $\mathrm{Na}^{+}$or ATP, is involved in the viability of hair cells.

\section{Localizing the problem}

Is $\mathrm{tTJ}$ localization of tricellulin required for its function? Recently, it has been reported that tricellulin is recruited to tTJs by the angulin family of membrane proteins, which consists of LSR, ILDR1, or ILDR2 (20). Interestingly, ILDR1 is causally linked to familial deafness DFNB42 (21). ILDR1 is the major type of angulin family protein in the inner ear, suggesting that the ILDR1tricellulin system may play a role at tTJs for hearing. Indeed, some DFNB42-associated ILDR1 mutant proteins are defective in tricellulin recruitment to $\mathrm{tTJ}$, and all DFNB49-associated tricellulin mutant proteins are defective in tTJ localization (22). It would be of interest to determine whether Ildr1-deficient mice exhibit a deafness phenotype accompanied by early hair cell degeneration, as was observed in the Tric ${ }^{R 497 X / R 497 X}$ mice.

The Tric ${ }^{R 497 X / R 497 X}$ mouse may also provide new insights into the human condition it was created to model. Although DFNB49 was previously reported as a form of nonsyndromic deafness, Tric ${ }^{R 497 X / R 497 X}$ mice exhibited morphological changes in several tissues, including the mandibular salivary gland, thyroid follicles, heart, and olfactory epithelium (17). Indeed, tricellulin is expressed ubiquitously and is predicted to be involved in establishing tricellular barriers in almost all epithelia. In particular, myocardial hypertrophy may be an issue, since patients with this problem are asymptomatic and only excessive exercise may bring on sudden cardiac death (23). The possibility that patients with DFNB49 hearing loss should have more frequent cardiology exams or perhaps avoid extreme exercise should be examined further.

\section{Conclusions}

Although tTJs were identified by electron microscopy about 40 years ago, many issues remain elusive regarding their structure and function. Further detailed analysis could clarify the molecular basis of tTJs and lead to the elucidation of their involvement in deafness pathogenesis. Understanding the structure and function of the inner ear and the details of its components is crucial for deciphering the senses of hearing and balance: how they perform normally, why they fail at times, and how we might be able to restore them in the future. The work of Riazuddin's team is an excellent step in this direction.

\section{Acknowledgments}

K.B. Avraham is supported by NIH (National Institute on Deafness and Other Communication Disorders) (grant R01DC011835); I-CORE Gene Regulation in Complex Human Disease, Center No. 41/11; and Human Frontier Science Program (grant RGP0012/2012). M. Furuse is supported by a NEXT Program from the Japan Society for the Promotion of Science (JSPS) (LS084). T. Higashi is a research fellow of JSPS.

Address correspondence to: Karen B. Avraham, Department of Human Molecular Genetics and Biochemistry, Sackler Faculty of Medicine, Tel Aviv 69978, Israel. Phone: 972.3.640.6642; Fax: 972.3.640.9360; E-mail: karena@post.tau.ac.il.

1. Lin FR, Niparko JK, Ferrucci L. Hearing loss prevalence in the United States. Arch Intern Med. 2011;171(20):1851-1852.

2. Van Camp G, Smith RJH. Hereditary Hearing Loss Homepage. Hereditary Hearing loss Homepage Web site. http://hereditaryhearingloss.org. Updated June 3, 2013. Accessed July 17, 2013.

3. Richardson GP, de Monvel JB, Petit C. How the genetics of deafness illuminates auditory physiology. Annu Rev Physiol. 2011;73:311-334.

4. Bosher SK, Warren RL. Observations on the electrochemistry of the cochlear endolymph of the rat: a quantitative study of its electrical potential and ionic composition as determined by means of flame spectrophotometry. Proc R Soc Lond B Biol Sci. 1968;171(23):227-247.

5. Nunes FD, et al. Distinct subdomain organization and molecular composition of a tight junction with adherens junction features. J Cell Sci. 2006;119(pt 23):4819-4827.

6. Tsukita S, Furuse M, Itoh M. Multifunctional strands in tight junctions. Nat Rev Mol Cell Biol. 2001;2(4):285-293.

7. Bear MF, Connors BW, Paradiso MA. Neuroscience: Exploring the Brain. 3rd ed. Philadelphia, Pennsylvania, USA: Lippincott Williams \& Wilkins; 2006.

8. Wilcox ER, et al. Mutations in the gene encoding tight junction claudin-14 cause autosomal recessive deafness DFNB29. Cell. 2001;104(1):165-172.

9. Ben-Yosef T, et al. Claudin 14 knockout mice, a 
model for autosomal recessive deafness DFNB29, are deaf due to cochlear hair cell degeneration. Hum Mol Genet. 2003;12(16):2049-2061.

10. Nakano Y, et al. A claudin-9-based ion permeability barrier is essential for hearing. PLoS Genet. 2009;5(8):e1000610.

11. Kitajiri S, et al. Compartmentalization established by claudin-11-based tight junctions in stria vascularis is required for hearing through generation of endocochlear potential. J Cell Sci. 2004;117(pt 21):5087-5096.

12. Gow A, et al. Deafness in Claudin 11-null mice reveals the critical contribution of basal cell tight junctions to stria vascularis function. J Neurosci. 2004;24(32):7051-7062.

13. Walsh T, et al. Genomic duplication and overexpression of TJP2/ZO-2 leads to altered expression of apoptosis genes in progressive nonsyn- dromic hearing loss DFNA51. Am J Hum Genet. 2010;87(1):101-109.

14. Staehelin LA. Further observations on the fine structure of freeze-cleaved tight junctions. $J$ Cell Sci. 1973;13(3):763-786

15. Ikenouchi J, Furuse M, Furuse K, Sasaki H, Tsukita S, Tsukita S. Tricellulin constitutes a novel barrier at tricellular contacts of epithelial cells. J Cell Biol. 2005;171(6):939-945.

16. Riazuddin S, et al. Tricellulin is a tight-junction protein necessary for hearing. Am J Hum Genet. 2006;79(6):1040-1051.

17. Nayak G, et al. Tricellulin deficiency affects tight junction architecture and cochlear hair cells. J Clin Invest. 2013;123(9):4036-4049.

18. Boettger T, Hubner CA, Maier H, Rust MB, Beck FX, Jentsch TJ. Deafness and renal tubular acido- sis in mice lacking the $\mathrm{K}-\mathrm{Cl}$ co-transporter $\mathrm{Kcc} 4$. Nature. 2002;416(6883):874-878.

19. Boettger T, et al. Loss of K-Cl co-transporter KCC3 causes deafness, neurodegeneration and reduced seizure threshold. EMBOJ. 2003;22(20):5422-5434.

20. Masuda S, et al. LSR defines cell corners for tricellular tight junction formation in epithelial cells. J Cell Sci. 2011;124(pt 4):548-555.

21. Borck G, et al. Loss-of-function mutations of ILDR1 cause autosomal-recessive hearing impairment DFNB42. Am J Hum Genet. 2011;88(2):127-137.

22. Higashi T, et al. Analysis of the 'angulin' proteins LSR, ILDR1 and ILDR2 - tricellulin recruitment, epithelial barrier function and implication in deafness pathogenesis. J Cell Sci. 2013;126(pt 4):966-977.

23. Maron BJ. Hypertrophic cardiomyopathy: a systematic review. JAMA. 2002;287(10):1308-1320. 